\title{
Evaluation of Residents' Comfort in High-Rise Residential Buildings in Dubai, United Arab Emirates
}

\author{
Chuloh Jung*, Jihad Awad and Nahla Al Qassimi \\ Department of Architecture, College of Architecture, art and Design, Ajman University, Ajman, United Arab Emirates
}

OPEN ACCESS

Edited by:

Ali Sohani,

K.N.Toosi University of

Technology, Iran

Reviewed by:

Rasikh Tariq,

Universidad Autónoma de Yucatán,

Mexico

Ehsan Saedpanah,

Tarbiat Modares University, Iran

Seyed Rahman Miremadi,

Shahid Beheshti University, Iran

${ }^{*}$ Correspondence:

Chuloh Jung

c.jung@ajman.ac.ae

Specialty section:

This article was submitted to

Sustainable Design and Construction,

a section of the journal

Frontiers in Built Environment

Received: 17 September 2021

Accepted: 19 October 2021

Published: 18 November 2021

Citation:

Jung C, Awad J and Al Qassimi N (2021) Evaluation of Residents Comfort in High-Rise Residential

Buildings in Dubai, United

Arab Emirates.

Front. Built Environ. 7:766057.

doi: 10.3389/fbuil.2021.766057
The global record of 1,700 \% urban footprint growth in only 38 years made Dubai one of the fastest growing cities in the world. The density of the metropolis population is approximately 762.6 individuals $/ \mathrm{km}^{2}$, and high-rise residential buildings in Dubai have reached 581,166 units (79\%) in 2020 and become a common residential type. The objective of this study is to provide basic data for the design of high-rise residential buildings in the future by evaluating the health of the residents of high-rise residential buildings in Dubai. As a methodology, the Todai Health Index, a structured health assessment tool, was used for high-rise residents' survey. For the analysis, the health evaluation data from residents were used as the dependent variable, and the number of living floors as the architectural characteristic and the indoor temperature and humidity condition as the residential environments were analyzed as the independent variable. The result had shown that residence floor is irrelevant to overall health, changes in the health status compared to those in the previous year, and the occurrence of daily disease health evaluation by the Todai Health Index. It was statistically proven that the thermal environment has a significant correlation with the residence floor, but the effect of the thermal environment on health was not strong. However, the humidity environment has a very strong relationship with the health of residents. The humidity environment has a very close relationship not only with the occurrence of daily diseases of residents but also with the health evaluation analyzed by the Todai Health Index. There is a significant relationship between the humidity environment and both physical and mental health. It was analyzed that a slightly humid condition had a positive effect on health.

Keywords: self-reported health evaluation, Todai Health Index, Princess Tower, indoor humidity, high-rise residential building

\section{INTRODUCTION}

After the oil boom of 1973, fast economic growth had occurred in Dubai with rapid population growth (Nassar et al., 2014). This unprecedented urbanization had created a massive immigration of foreign labor into Dubai, as well as domestic migration from rural to urban areas (Fazli and Faridi, 2008; Alawadi, 2017). The creation of new coastline over $300 \mathrm{~km}$ from reclamation, the rapid expansion of urban area, and the intensified real estate development made Dubai one of the most rapidly urbanized cities in human history (Acuto, 2010). The total buildup area had been increased from only $54 \mathrm{~km}^{2}$ in 1975 to $977 \mathrm{~km}^{2}$ in 2015 (LULUC, 2021; Buckley \& Hanieh, 2014). The global record of $1,700 \%$ urban footprint growth in only 38 years made Dubai one of the fastest growing 
cities in the world (Ewers, 2017). Dubai's population was 166,000 in 1975 and expanded to 2,921,376 in 2021 (Alawadi \& Benkraouda, 2019). The metropolis area of Dubai is only $35 \mathrm{~km}^{2}$ from $4,114 \mathrm{~km}^{2}$ of the total Dubai area (Elessawy, 2017). The density of the metropolis population is approximately 762.6 individuals per square kilometer (Breslow, 2020). High-rise residential buildings in Dubai have reached 581,166 units (79\%) in 2020 and become a common residential type (Dubai Statistics Center, 2021). However, it has been pointed out that the effect of high-rise residential buildings on the health of residents has not been clearly verified (Larcombe et al., 2019). In other countries, there have been intermittent reports that high-rise living has a negative effect on the health of residents (Lee, 2014; Xue et al., 2016b). These reports indicate that the higher floor you live, the more negative impact on the health of the residents (Cho \& Lee, 2011). This presupposes that the primary architectural factor affecting the health of residents is the number of residential floors (Barros et al., 2019; Foster et al., 2020). However, there are very few studies on this topic in the UAE, and it is difficult to apply the results of foreign studies in Dubai since lifestyle and building systems are different from those of other countries (Ahmed, 2012; Generalova, 2018). Therefore, this study aims to provide basic data for the design of high-rise residential buildings in the future by evaluating the residents' health in high-rise residential buildings in Dubai and understanding the degree of influence by architectural factors.

\section{LITERATURE REVIEW}

\section{The Definition of Health and Influential Factors}

The health of residents is a complicated concept of various factors (Barros et al., 2019; Ahn et al., 2021). The WHO's definition of health, promulgated in 1948, is health is a state of complete physical, mental, and social well-being and not merely the absence of disease or infirmity (Sivakumar et al., 2019; Meier, 2010), and this definition has not been revised since 1948. Thus, by definition, health does not simply refer to the presence or absence of disease (Wong et al., 2017; Manyazewal, 2017). It is a concept that encompasses not only the physical aspect but also the mental aspect and even the social aspect (Larcombe et al., 2019; Ige et al., 2019). According to this definition, not being healthy includes disease, but it is reasonable to view it as a concept that includes not only disease as a specific medical practice but also physical and mental discomfort or other health problems experienced in general (Xue F. et al., 2016).

Most of the studies dealing with the living environment and the health of residents are divided into three types: first, the type that deals with the relationship between the residential environment and the psychological health of residents (Choi \& Matz-Costa, 2018); second, the type that deals with the relationship between the living environment and physical health (Van den Berg et al., 2015); and third, the type that deals with the relationship between the residential environment and behavioral characteristics (Van Cauwenberg et al., 2011). Moreover, in the case of dealing with the residential environment, it is roughly divided into two groups: first, the case of studying architectural characteristics such as the number of floors, size, and type of residence (Emmanuel et al., 2020), and second, the case of studying the environmental conditions of the living space such as indoor air, temperature, and humidity (Ghaffarianhoseini et al., 2018; Nguyen et al., 2014). Recently, in addition to this, sick building syndrome (SBS), which pays attention to harmful substances emitted by buildings, is being discussed as a factor affecting health (Jafari et al., 2015; Lu et al., 2018).

The architectural characteristics of a residential building may be a factor affecting health but, in most cases, health is often affected by the characteristics of the residential environment (Takigawa et al., 2012; Crook and Burton, 2010). The emission of harmful substances is directly affected through the environmental conditions of the residential building as these hazardous substances are directly related to the indoor air environment (Wolkoff, 2018; Tham, 2016). Therefore, in order to understand the correlation between the residential building and the residents' health, it is difficult to understand the correlation by simply paying attention to the architectural characteristics of the residential space (Steinemann et al., 2017; Persily and Emmerich, 2012). This means that it is necessary to analyze not only architectural characteristics but also indoor environmental conditions as influencing factors in order to understand the interrelationship between the residential space and residents' health (Guyot et al., 2018).

\section{The Review of Self-Reported Health Evaluation Tools}

In order to analyze the effect of the living environment on health, it is necessary to explore the objective measurement of health status (Lin et al., 2013). In the field of medicine and health, various standard measurement tools have been developed and used not only to define health but also to evaluate general health rather than disease (Anhang Price et al., 2014).

\section{Self-Assessed General Health}

There are two types of single-item indicators: 3-point scale and 5point scale. The 5-point scale is used as an international standard, and the stability of the results has been verified for a long time ( $\mathrm{Au}$ and Johnston, 2014). However, since it is a single item, it may be pointed out that it has rigid characteristics with respect to factors that interfere with measurement or lack of accurate explanation for the actual situation (Doiron et al., 2015). Nevertheless, it can be used as a useful indicator to understand the state of health or the trend of change for the general public and has the advantage of being administratively convenient (Hu et al., 2016).

\section{SF-36}

It was originally started in the United States, but there is also a format adapted to the situation in the United Kingdom (Lins \& Carvalho, 2016). This measurement tool has been developed since the 1980s and has been widely used not only in the medical field but also as a tool for general health status evaluation (Burholt \& 
Nash, 2011). The stability has been verified experimentally. The content consists of eight areas and 36 items. The U.K. Department of Health used it in the 1996 Health Survey for England (HSE). Currently, it has become the most useful tool for establishing health management policies for the general public in health policy (ten Klooster et al., 2013). Eight domains including mental health are recognized as reliable.

\section{SF-20}

It is composed of 20 items by adding one item of pain area and one item of social function to the 18 item survey tool conducted by Louis Harris of the United States in 1984. It was originally developed as a tool for the Medical Outcomes Study (MOS). It consists of six domains: general health, pain, physical functioning, social functioning, role functioning, and mental health (Baghianimoghadam et al., 2011). The subitems consist of a total of 20 items, and the response time is usually $4-5 \mathrm{~min}$. Reliability is secured to some extent but not high, and it has been employed and used by the Centers for Disease Control and Prevention in Denver, United States.

\section{GHQ-12}

It is a tool designed to identify individuals with mental health problems within a group. It has been used as the central method of the British Household Panel Survey (BHPS) since 1991 (Lesage et al., 2011). It is evaluated as an appropriate tool for measuring mental health on the premise of a long-term investigation. It is used in surveys involving large population groups (Smith et al., 2010).

\section{RAND-36}

Basically, it is a tool almost similar to the MOS SF-36, but it is a multidimensional measurement tool for health with partial modifications. The partial revision was not the revision of the survey items, but the method of summing the items, and the survey contents were the same as in SF-36 (Saimanen et al., 2019).

\section{NHP}

It is a self-response health evaluation index for adults as the main survey target as an index briefly indicating the emotional and physical state of the disease bearer (Busija et al., 2011). It consists of a total of 45 items and is one of the representative multi-item self-response health measurement tools along with SF-36. The measurement tool consists of two parts: part 1 consists of a total of 38 items in six subareas and part 2 is to answer only "yes" or "no" to how much discomfort you are experiencing in seven areas of life. However, since this measurement tool measures the health status of patients, rather than the general public, it is a suitable measurement tool for the chronically ill or the elderly (Tabali et al., 2012).

\section{EQ-5D}

Through five question items (mobility, independent behavior, daily life, pain/comfort, and anxiety/depression), each item is asked to respond on three scales. This method assigns the weights to the five-digit number system. Regarding the weights, the accumulation of empirical studies is used as a separate weighting index. This measurement tool pursues the sophistication of weights by continuously accumulating data from each country through EQ-net, centering on Europe (Sullivan et al., 2011). However, it is judged to have limitations in measuring comprehensive health because the evaluation items are limited (Van Hout et al., 2012).

\section{Todai Health Index}

Based on the Cornell Medical Index (CMI), the THI was developed at the University of Tokyo to develop the health questionnaire by adjusting it to match the characteristics of Asians (Suzuki, 2017). Todai is the Japanese pronunciation of the University of Tokyo. The total consists of 130 question items, with five categories of physical health and seven categories of mental and behavioral areas, and a total of 12 categories. In addition to the analysis of 12 categories, the Todai Health Index is designed to calculate the mental and physical tendency and the neurotic tendency through discriminant analysis (Trieu et al., 2021). However, it cannot be judged uniformly, and it is necessary to determine the analysis method according to the purpose of the study. In some studies, only some of the 12 categories of the Todai Index are extracted and used for research. All 130 questions are to be answered in three ways: 1) often, 2) sometimes, and 3) not at all or all. This is the case of the English version of the Todai Index. In the case of the Japanese version, slightly different response items are mixed depending on the nature of the question (Murayama et al., 2019). In the process of interpreting the response result, as well as using the summed score of the items included in each scale, if the score is less than a certain point, it is judged that there is a problem (Furutani et al., 2020). However, in some cases, it is recommended to interpret not only the score but also the degree of the position of the total score in the entire survey subject as a percentile concept.

\section{The Review of Self-Reported Health Evaluation Tools}

Most of the reliability problems of various self-response health evaluation tools have been verified. However, since there may be advantages and disadvantages depending on the purpose, the following selection principles were considered to select an appropriate evaluation tool: 1) The focus should be on the general health evaluation of the general public, rather than the patient; 2) as a multi-item measurement tool, rather than a singleitem question, multifaceted aspects of general health should be included; 3) questions that express concrete states, rather than abstract questions, should be constructed; 4) the response should not take much time; and 5) it should be composed of items that do not feel rejected when responding.

The evaluation tool that best met the previous selection principle was determined to be the Todai Health Index. SF36 and Rand-36 are also the measurement tools used for both the general public and patient populations (Garratt \& Stavem, 2017). However, in reality, there is a stronger tendency to presuppose the condition of the person with the disease. There was a limitation partially inconsistent with the nature of this study targeting the general public. In the case of the 


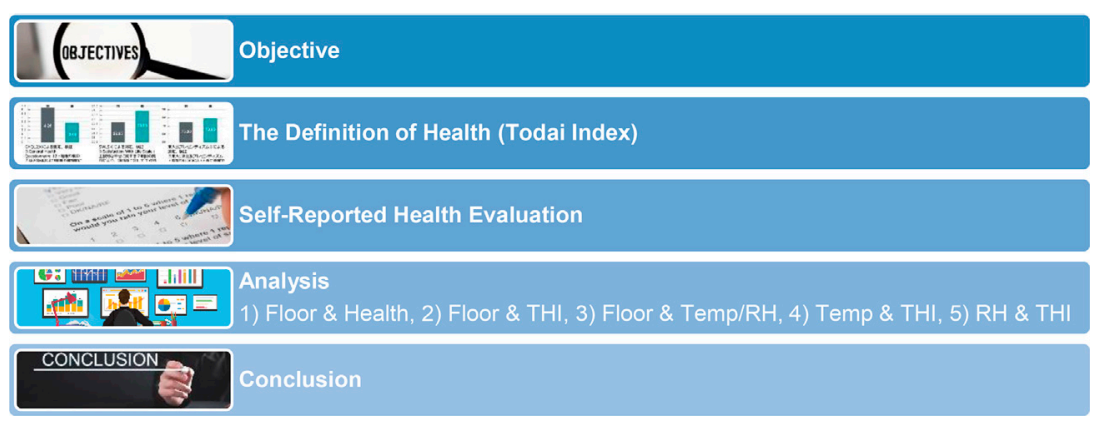

FIGURE 1 | Flow of research process.

general public, there may be a sense of rejection when responding. Although the GHQ-12 is a relatively simple and commonly used measurement tool, it is focused on measuring mental health (Lindkvist and Feldman, 2016). The Todai Health Index may be the most appropriate target in terms of its content, but the total number of questions is 130 , which puts a burden on the number of responses (Kim et al., 2010). If a problem with a large number of questions is tolerated without any limitation, this study conducted a health evaluation using the Todai Index as the most appropriate index. Residents' health in high-rise residential buildings in Dubai had never been evaluated with any self-reported health evaluation tools, even though Dubai is one of the most well-known cities of skyscrapers.

\section{METHODOLOGY}

The subject of this study is limited to high-rise residential buildings in Dubai since comparative research between lowrise and high-rise residential buildings cannot define the characteristics of the residents of high-rise residential buildings (Acuto, 2010). Moreover, there is no confirmation that the socioeconomic class of residents of low-rise and highrise residential buildings is the same (Barr and Johnson, 2020). This is because the area in Dubai is also difficult to be defined as one metropolitan area, so it was judged that it was more advantageous in terms of the purity of the sample to limit the residents of high-rise residential buildings and conduct comparative analysis by residence floors such as low-rise, mid-rise, and high-rise residential areas. In addition, the analysis subjects were limited to adults. The health of residents is likely to show various characteristics according to age. Both physical and mental health were included for health status evaluation. Chronic diseases were excluded because it was judged that if chronic diseases were included, it would cause distortion in verifying the effects of the living environment. For the health survey, self-reported health evaluation was used for adults. Self-reported health evaluation refers to a respondent's self-assessment of their health according to the questionnaire and is widely used in the United States and European countries, and various measurement tools have been developed (Subedi and
Rosenberg, 2014). In the case of the United States, the selfresponse evaluation method has been verified to have considerable validity and reliability in predicting health, disease, and mortality (Lee et al., 2013; Zimmerman and Anderson, 2019). In this study, Japan's Todai Health Index, a structured health assessment tool, was used for various selfresponse health assessments (Kim et al., 2010). For the analysis, the health evaluation data responded to by residents were used as the dependent variable, and the number of living floors as the architectural characteristic and the indoor temperature and humidity condition as the residential environment characteristic were analyzed as the independent variable. In addition, the verification of differences in health evaluation according to the characteristics of residents was also conducted (Figure 1).

\section{ANALYSIS}

\section{General Information of Surveyors}

The survey was conducted for the Princess Tower in Dubai (Figure 2). This residential tower was built relatively early in Dubai urbanization, and the residents have 10 years of living experience, which is longer than other high-rise residential towers in Dubai. The scale is on the $101^{\text {st }}$ floor with a height of $413 \mathrm{~m}$, and it was the tallest high-rise residential tower in Dubai (Figure 3) before Marina $101\left(425 \mathrm{~m}, 101^{\text {st }}\right.$ floor) was completed (Safarik et al., 2018). Other high-rise residential towers in Dubai, such as the Executive Towers in Business Bay and Marina 101 in Dubai Marina, were also considered, but the Princess tower was selected because it was judged that it was useful to secure the homogeneity of the respondents because 763 housing units live in the same building (Figure 4) (Kalantari and Shepley, 2020). The survey was conducted by sending an email and receiving a reply with the permission of the Princess Tower residential board. The survey was conducted between January 9 and March 18, 2021, and some additional questionnaires were collected.

The average age of the respondents was 39.97 years, and the average age of the residents of each floor was almost the same. The number of families is 3.61, which also shows no difference according to the residence by floor. The gender distribution of the respondents did not show any differences by floor, so the 


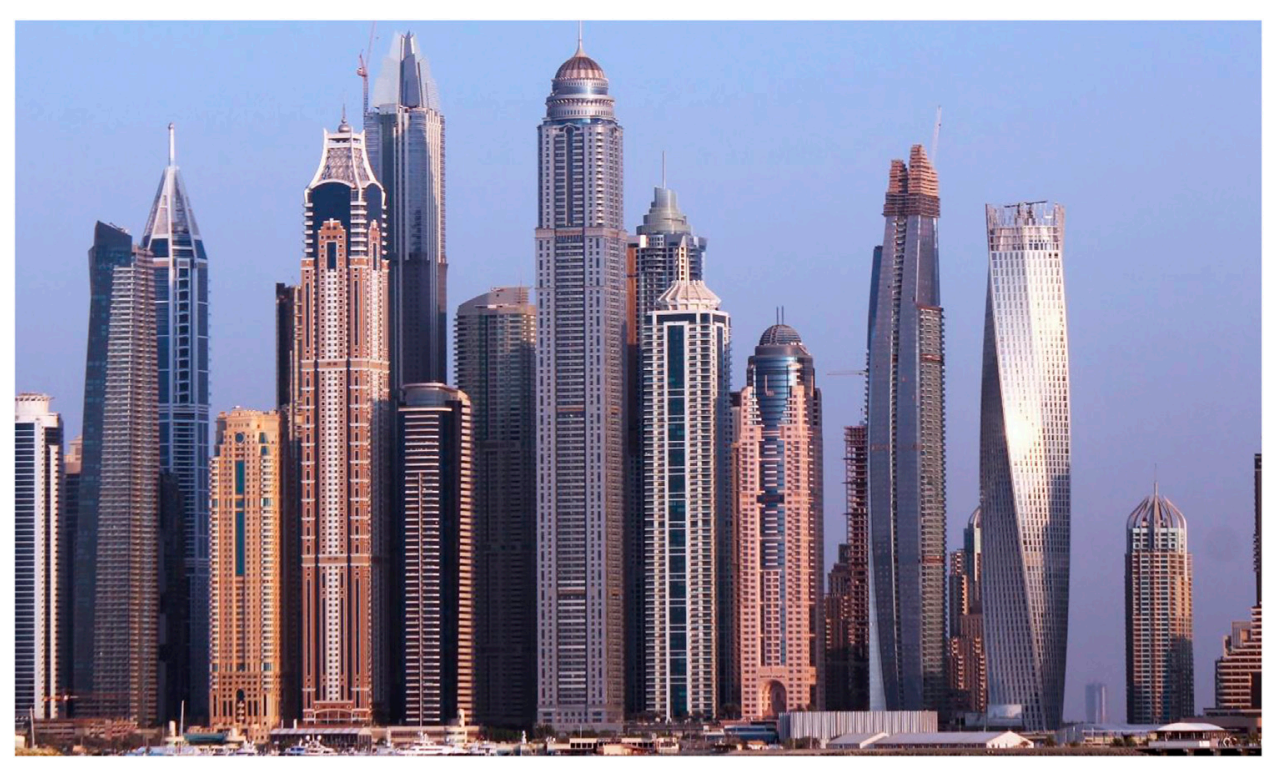

FIGURE 2 | Princess Tower in Dubai, UAE.

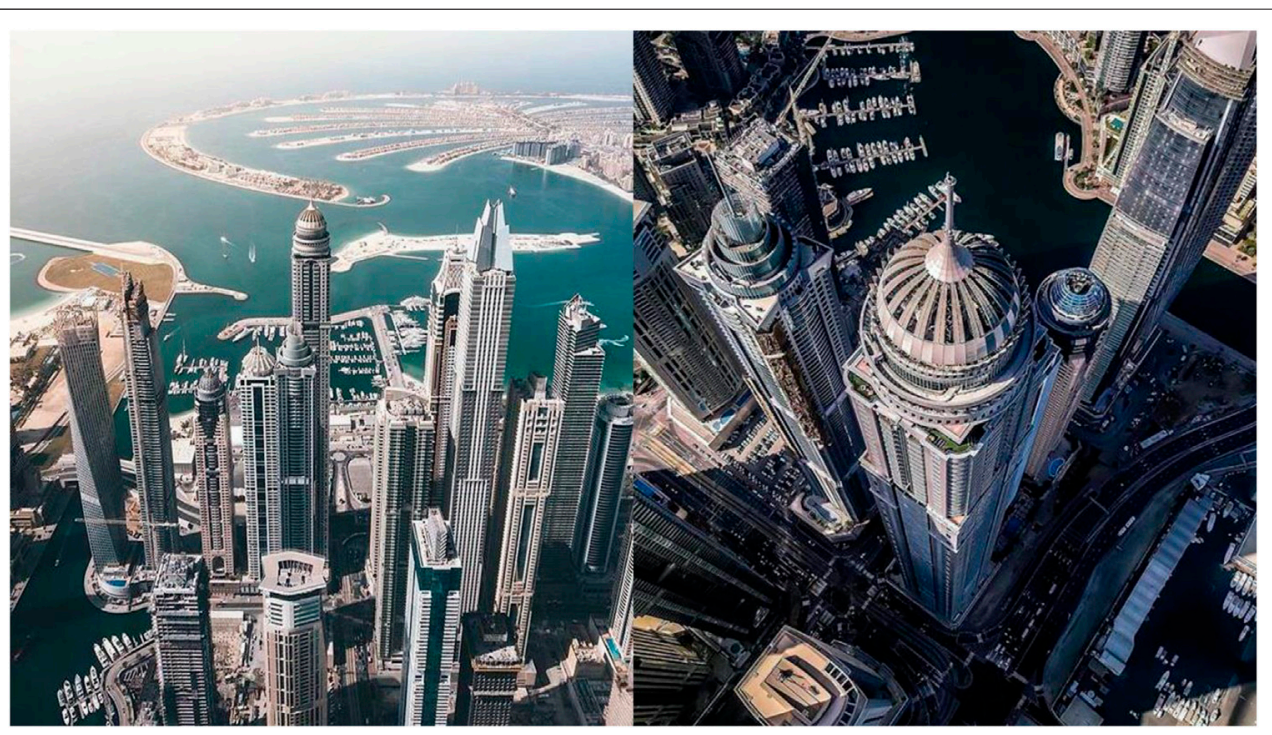

FIGURE $\mathbf{3}$ | Context of the Princess Tower.

respondents were identified as a homogeneous group, regardless of the number of living floors. The average residence period of the current house is 49.45 months, and there is no difference depending on the number of floors (Table 1).

\section{Residence Floor and Health}

The general health status of residents was overall above average. It does not show any difference by the number of living floors, so it was analyzed that the current number of living floors did not have a relationship with the general health status. In order to investigate in more detail, the health status compared with the previous year was evaluated. Since a certain period of residence is required for the analysis, only respondents who have lived for more than 2 years were analyzed, and this analysis did not show any differences by floor. More than half of the respondents answered that they were similar, and the response of good status was slightly higher than that of bad status, the negative effect of living in a high-rise building on health was not verified (Table 2).

Since Dubai population is composed of $15 \%$ native residents and $85 \%$ of expatriates and majority locals live in an independent villa, our target audience of expatriates, who live in high-rise 


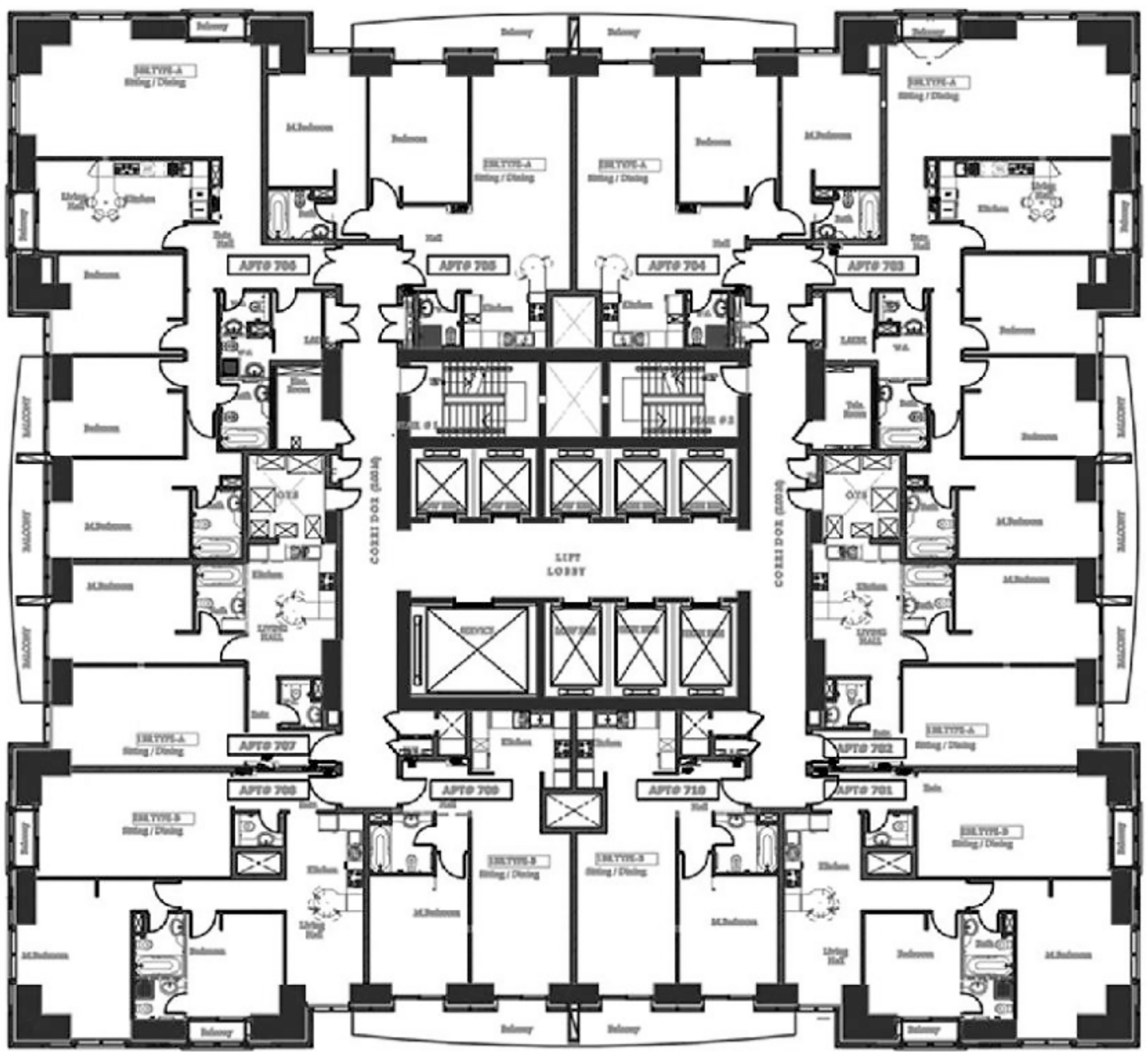

FIGURE 4 | Typical plan of the Princess Tower.

TABLE 1 | General information of surveyors and residence period per floor.

\begin{tabular}{|c|c|c|c|c|c|c|c|}
\hline \multirow[t]{2}{*}{ Residence floor } & \multirow[t]{2}{*}{ Age (years) } & \multirow{2}{*}{$\begin{array}{c}\text { Number of } \\
\text { family }\end{array}$} & \multicolumn{2}{|c|}{ Gender } & \multirow{2}{*}{$\begin{array}{l}\text { Average residence } \\
\text { period (months) }\end{array}$} & \multirow{2}{*}{$\begin{array}{l}\text { Number of } \\
\text { response }\end{array}$} & \multirow[t]{2}{*}{ Standard deviation } \\
\hline & & & Male & Female & & & \\
\hline $1-20$ & 40.19 & 3.65 & 11 & 92 & 52.46 & 101 & 36.13 \\
\hline $41-60$ & 40.92 & 3.59 & 21 & 98 & 46.14 & 112 & 33.95 \\
\hline $61-80$ & 40.37 & 3.63 & 20 & 93 & 53.63 & 109 & 34.38 \\
\hline $81-100$ & 39.10 & 3.60 & 26 & 108 & 47.91 & 128 & 36.98 \\
\hline Average or total & 39.97 & 3.62 & 91 & 504 & 49.45 & 573 & 35.41 \\
\hline
\end{tabular}


TABLE 2 | Evaluation of general health status and comparison with previous year status by residence floor.

\begin{tabular}{|c|c|c|c|c|c|c|c|}
\hline \multirow[t]{2}{*}{ Period } & \multirow[t]{2}{*}{ Health status } & \multicolumn{5}{|c|}{ Current residence floor } & \multirow[t]{2}{*}{ Total } \\
\hline & & $1-20$ & $21-40$ & $41-60$ & $61-80$ & $81-100$ & \\
\hline \multirow[t]{7}{*}{ Current year (2020) health status } & Excellent & $11(10.9)$ & $18(14.8)$ & $14(11.9)$ & $18(16.1)$ & $14(10.5)$ & $75(12.8)$ \\
\hline & Good & $19(18.8)$ & $40(32.8)$ & $26(22.0)$ & $24(21.4)$ & $45(33.8)$ & $154(26.3)$ \\
\hline & Average & $48(47.5$ & $42(34.4)$ & $58(49.2)$ & $55(49.1)$ & 54 (40.6) & 257 (43.9) \\
\hline & Worse & $20(19.8)$ & $20(16.4)$ & $16(13.6)$ & $14(12.5)$ & $16(12.0)$ & $86(14.7)$ \\
\hline & Worst & $3(3.0)$ & $2(1.6)$ & $4(3.4)$ & $1(0.9)$ & $4(3.0)$ & $14(2.4)$ \\
\hline & Total & 101 (100.0) & $122(100.0)$ & $118(100.0)$ & $112(100.0)$ & $133(100.0)$ & $586(100.0)$ \\
\hline & Chi-square & \multicolumn{6}{|c|}{20.916 N.S } \\
\hline \multirow[t]{7}{*}{ Last year (2019) health status } & Excellent & $1(1.4)$ & $3(3.8)$ & $5(7.2)$ & $6(7.9)$ & $6(7.6)$ & $21(5.6)$ \\
\hline & Good & $16(22.5)$ & $19(23.8)$ & $14(20.3)$ & $15(19.7)$ & 15 (19.0) & $79(21.1)$ \\
\hline & Average & 43 (60.6) & $46(57.5)$ & $32(46.4)$ & $44(57.9)$ & $41(51.9)$ & 206 (54.9) \\
\hline & Worse & 8 (11.3) & $11(13.8)$ & $16(23.2)$ & $10(13.2)$ & $14(17.7)$ & $59(15.7)$ \\
\hline & Worst & $3(4.2)$ & $1(1.3)$ & $2(2.9)$ & 1 (1.3) & $3(3.8)$ & $10(2.7)$ \\
\hline & Total & 71 (100.0) & 80 (100.0) & 68 (100.0) & 76 (100.0) & 79 (100.0) & 375 (100.0) \\
\hline & Chi-square & \multicolumn{6}{|c|}{12.815 N.S } \\
\hline
\end{tabular}

TABLE 3 | Experience of health problems in winter by residence floor.

Symptom

Current residence floor

Total

\begin{tabular}{|c|c|c|c|c|c|c|c|}
\hline & \multirow{2}{*}{\multicolumn{2}{|c|}{$1-20$}} & & & & & \multirow{2}{*}{ 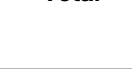 } \\
\hline & & & $21-40$ & $41-60$ & $61-80$ & $81-100$ & \\
\hline \multirow[t]{3}{*}{ Respiratory Disorder } & Yes & $92(88.5)$ & 107 (88.4) & 101 (87.8) & 105 (94.6) & $114(87.7)$ & 519 (89.3) \\
\hline & No & $12(11.5)$ & $14(11.6)$ & $14(12.2)$ & $6(5.4)$ & $16(12.3)$ & $62(10.7)$ \\
\hline & Total & 104 (100.0) & $121(100.0)$ & 115 (100.0) & $111(100.0)$ & $130(100.0)$ & $581(100.0)$ \\
\hline Chi-Square & \multicolumn{7}{|c|}{4.051 N.S. } \\
\hline \multirow[t]{3}{*}{ Skin Disorder } & Yes & 39 (43.3) & $36(36.0)$ & $40(43.5)$ & $44(46.8)$ & $44(40.4)$ & 203 (41.9) \\
\hline & No & $51(56.7)$ & $64(64.0)$ & $52(56.6)$ & $50(53.2)$ & $65(59.6)$ & $282(58.1)$ \\
\hline & Total & $90(100.0)$ & $100(100.0)$ & $92(100.0)$ & $94(100.0)$ & 109 (100.0) & 485 (100.0) \\
\hline Chi-Square & \multicolumn{7}{|c|}{2.636 N.S. } \\
\hline \multirow[t]{3}{*}{ Allergies } & Yes & $30(34.5)$ & $34(35.8)$ & $34(37.0)$ & $30(35.7)$ & $46(43.0)$ & $174(37.4)$ \\
\hline & No & $57(65.5)$ & $61(64.2)$ & $58(63.0)$ & $54(64.3)$ & $61(57.0)$ & $291(62.6)$ \\
\hline & Total & 87 (100.0) & $95(100.0)$ & $92(100.0)$ & $84(100.0)$ & 107 (100.0) & 465 (100.0) \\
\hline Chi-Square & \multicolumn{7}{|c|}{1.959 N.S. } \\
\hline \multirow[t]{3}{*}{ Digestive Disorder } & Yes & 47 (53.4) & $53(53.5)$ & $56(57.7)$ & $54(61.4)$ & 68 (63.6) & $278(58.0)$ \\
\hline & No & 41 (46.6) & $46(46.5)$ & $41(42.3)$ & $34(38.6)$ & $39(36.4)$ & $201(42.0)$ \\
\hline & Total & 88 (100.0) & $99(100.0)$ & 97 (100.0) & 88 (100.0) & 107 (100.0) & 479 (100.0) \\
\hline Chi-Square & \multicolumn{7}{|c|}{ 3.337 N.S. } \\
\hline \multirow[t]{3}{*}{ Eye Disorder } & Yes & $34(40.5)$ & $30(33.0)$ & 36 (37.9) & $38(44.7)$ & 37 (36.6) & $175(38.4)$ \\
\hline & No & $50(59.5)$ & $61(67.0)$ & $59(62.1)$ & $47(55.3)$ & $64(63.4)$ & $281(61.6)$ \\
\hline & Total & $84(100.0)$ & 91 (100.0) & 95 (100.0) & 85 (100.0) & 101 (100.0) & 456 (100.0) \\
\hline Chi-Square & \multicolumn{7}{|c|}{2.862 N.S. } \\
\hline \multirow[t]{3}{*}{ Pain } & Yes & $45(51.5)$ & $59(60.2)$ & 64 (65.3) & $58(62.4)$ & 65 (61.3) & $291(60.2)$ \\
\hline & No & $43(48.9)$ & $39(39.8)$ & $34(34.7)$ & $35(37.6)$ & $41(38.7)$ & $192(39.8)$ \\
\hline & Total & 88 (100.0) & 98 (100.0) & 98 (100.0) & 93 (100.0) & 106 (100.0) & 483 (100.0) \\
\hline Chi-Square & \multicolumn{7}{|c|}{4.323 N.S. } \\
\hline \multirow[t]{3}{*}{ Other Disorders } & Yes & $49(57.0)$ & 57 (58.2) & $58(59.8)$ & $51(58.0)$ & 66 (62.3) & $281(59.2)$ \\
\hline & No & 37 (43.0) & $41(41.8)$ & $39(40.2)$ & $37(42.0)$ & $40(37.7)$ & $194(40.8)$ \\
\hline & Total & 86 (100.0) & $98(100.0)$ & 97 (100.0) & 88 (100.0) & 106 (100.0) & 475 (100.0) \\
\hline
\end{tabular}

Chi-Square

0.702 N.S.

residential buildings, is mostly on vacation in summer due to the scorching weather of Dubai. This is the main reason why the survey was conducted in winter. Moreover, Dubai residents have more health problems in winter due to dramatic temperature change from $41^{\circ} \mathrm{C}$ (night) $/ 31^{\circ} \mathrm{C}$ (day) in summer to $24^{\circ} \mathrm{C}$ (night)/ $15^{\circ} \mathrm{C}$ (day) in winter. 
TABLE 4 | 12 scales Todai Health Index average score by residence floor (residents over 2 Years).

\begin{tabular}{|c|c|c|c|c|c|c|c|c|c|c|c|c|c|}
\hline Floor & & $\begin{array}{c}\text { Vague } \\
\text { complaints }\end{array}$ & Respiratory & $\begin{array}{l}\text { Eye and } \\
\text { skin }\end{array}$ & $\begin{array}{c}\text { Mouth } \\
\text { and anal }\end{array}$ & Digestive & Irritability & $\begin{array}{l}\text { Lie } \\
\text { scale }\end{array}$ & $\begin{array}{c}\text { Mental } \\
\text { instability }\end{array}$ & Depression & Aggression & Nervousness & $\begin{array}{l}\text { Irregularity } \\
\text { of life }\end{array}$ \\
\hline \multirow[t]{3}{*}{$1-20$} & Mean & 2.390 & 2.613 & 2.500 & 2.580 & 2.555 & 2.223 & 2.177 & 2.230 & 2.354 & 2.255 & 2.064 & 2.311 \\
\hline & $\mathrm{N}$ & 62 & 65 & 69 & 68 & 68 & 71 & 68 & 65 & 68 & 71 & 68 & 68 \\
\hline & S.D. & 0.340 & 0.325 & 0.332 & 0.276 & 0.335 & 0.361 & 0.278 & 0.375 & 0.334 & 0.278 & 0.342 & 0.261 \\
\hline \multirow[t]{3}{*}{$21-40$} & Mean & 2.358 & 2.532 & 2.457 & 2.525 & 2.492 & 2.125 & 2.086 & 2.242 & 2.311 & 2.263 & 1.990 & 2.262 \\
\hline & $\mathrm{N}$ & 75 & 78 & 79 & 79 & 78 & 79 & 79 & 77 & 76 & 78 & 80 & 77 \\
\hline & S.D. & 0.336 & 0.328 & 0.375 & 0.347 & 0.352 & 0.353 & 0.254 & 0.382 & 0.362 & 0.255 & 0.441 & 0.258 \\
\hline \multirow[t]{3}{*}{$41-60$} & Mean & 2.288 & 2.534 & 2.449 & 2.495 & 2.476 & 2.096 & 2.143 & 2.250 & 2.313 & 2.219 & 1.974 & 2.249 \\
\hline & $\mathrm{N}$ & 64 & 66 & 65 & 61 & 67 & 67 & 69 & 66 & 68 & 67 & 64 & 65 \\
\hline & S.D. & 0.401 & 0.334 & 0.338 & 0.370 & 0.398 & 0.424 & 0.298 & 0.366 & 0.397 & 0.349 & 0.448 & 0.286 \\
\hline \multirow[t]{3}{*}{$61-80$} & Mean & 2.402 & 2.611 & 2.514 & 2.601 & 2.549 & 2.093 & 2.174 & 2.216 & 2.290 & 2.244 & 2.065 & 2.268 \\
\hline & $\mathrm{N}$ & 71 & 69 & 70 & 71 & 70 & 70 & 71 & 70 & 72 & 76 & 71 & 71 \\
\hline & S.D. & 0.300 & 0.311 & 0.399 & 0.279 & 0.366 & 0.344 & 0.288 & 0.331 & 0.349 & 0.277 & 0.425 & 0.235 \\
\hline \multirow[t]{3}{*}{$81-100$} & Mean & 2.377 & 2.565 & 2.437 & 2.548 & 2.529 & 2.098 & 2.109 & 2.193 & 2.296 & 2.269 & 1.952 & 2.253 \\
\hline & $\mathrm{N}$ & 73 & 76 & 74 & 77 & 76 & 77 & 76 & 74 & 78 & 79 & 77 & 75 \\
\hline & S.D. & 0.371 & 0.297 & 0.367 & 0.308 & 0.346 & 0.333 & 0.265 & 0.385 & 0.339 & 0.301 & 0.391 & 0.242 \\
\hline \multirow[t]{3}{*}{ Total } & Mean & 2.364 & 2.570 & 2.471 & 2.550 & 2.520 & 2.127 & 2.136 & 2.226 & 2.311 & 2.251 & 2.008 & 2.268 \\
\hline & $\mathrm{N}$ & 345 & 354 & 357 & 356 & 359 & 364 & 363 & 352 & 362 & 371 & 360 & 356 \\
\hline & S.D. & 0.351 & 0.319 & 0.363 & 0.318 & 0.359 & 0.364 & 0.277 & 0.367 & 0.355 & 0.291 & 0.412 & 0.256 \\
\hline Sig & & N.S. & N.S. & N.S. & N.S. & N.S. & N.S. & N.S. & N.S. & N.S. & N.S. & N.S. & N.S. \\
\hline
\end{tabular}


TABLE 5 | Comparison between THI physical categories and THI mental categories by residence floor.

Current residence floor

$1-20$
$21-40$
$41-60$
$61-80$
$81-100$

Average

\section{THI physical categories}

\section{Mean}

2.493

2.499

2.463

2.526

2.511

2.498
THI mental categories

F-text

$0.701 \mathrm{NS}$

2.204

2.184

2.201

2.200

2.159

2.188

TABLE 6 | Evaluation of indoor temperature and humidity status by residence floor.

\begin{tabular}{|c|c|c|c|c|c|c|c|}
\hline \multirow[t]{2}{*}{ Period } & \multirow[t]{2}{*}{ Status } & \multicolumn{5}{|c|}{ Current residence floor } & \multirow[t]{2}{*}{ Total } \\
\hline & & $1-20$ & $21-40$ & $41-60$ & $61-80$ & $81-100$ & \\
\hline \multirow[t]{7}{*}{ Temperature } & Very warm & 10 (10.3) & 7 (5.8) & $9(7.8)$ & 7 (6.3) & 8 (6.2) & $41(7.1)$ \\
\hline & Warm & $27(27.8)$ & $51(42.1)$ & $44(37.9)$ & 44 (39.6) & 48 (37.2) & 214 (37.3) \\
\hline & Moderate & $27(27.8)$ & $45(27.2)$ & $48(41.4)$ & $49(44.1)$ & 47 (36.4) & 216 (37.6) \\
\hline & Cold & 28 (28.9) & $17(14.0)$ & $14(12.1)$ & $10(9.0)$ & 24 (18.6) & 93 (16.2) \\
\hline & Very Cold & $5(5.2)$ & $1(0.8)$ & $1(0.9)$ & $1(0.9)$ & 2 (1.6) & $10(1.7)$ \\
\hline & Total & 97 (100.0) & $121(100.0)$ & 116 (100.0) & $111(100.0)$ & 129 (100.0) & $100(100.0)$ \\
\hline & Chi-Square & \multicolumn{6}{|c|}{$32.723^{\star \star \star}$} \\
\hline \multirow[t]{6}{*}{ Humidity } & Very dry & 18 (18.4) & 23 (19.2) & $13(11.2)$ & $17(15.2)$ & $16(12.4)$ & $87(15.1)$ \\
\hline & Dry & 58 (59.2) & 69 (57.5) & 80 (69.0) & 73 (65.2) & 80 (62.0) & 360 (62.6) \\
\hline & Moderate & $21(21.4)$ & 28 (23.3) & 21 (18.1) & 17 (15.2) & 27 (20.9) & $114(19.8)$ \\
\hline & Humid & $1(1.0)$ & $0(0.0)$ & $2(1.7)$ & $5(4.5)$ & $6(4.7)$ & $14(2.4)$ \\
\hline & Total & 98 (100.0) & $120(100.0)$ & $116(100.0)$ & $112(100.0)$ & 129 (100.0) & 575 (100.0) \\
\hline & Chi-Square & \multicolumn{6}{|c|}{ 16.153 N.S. } \\
\hline
\end{tabular}

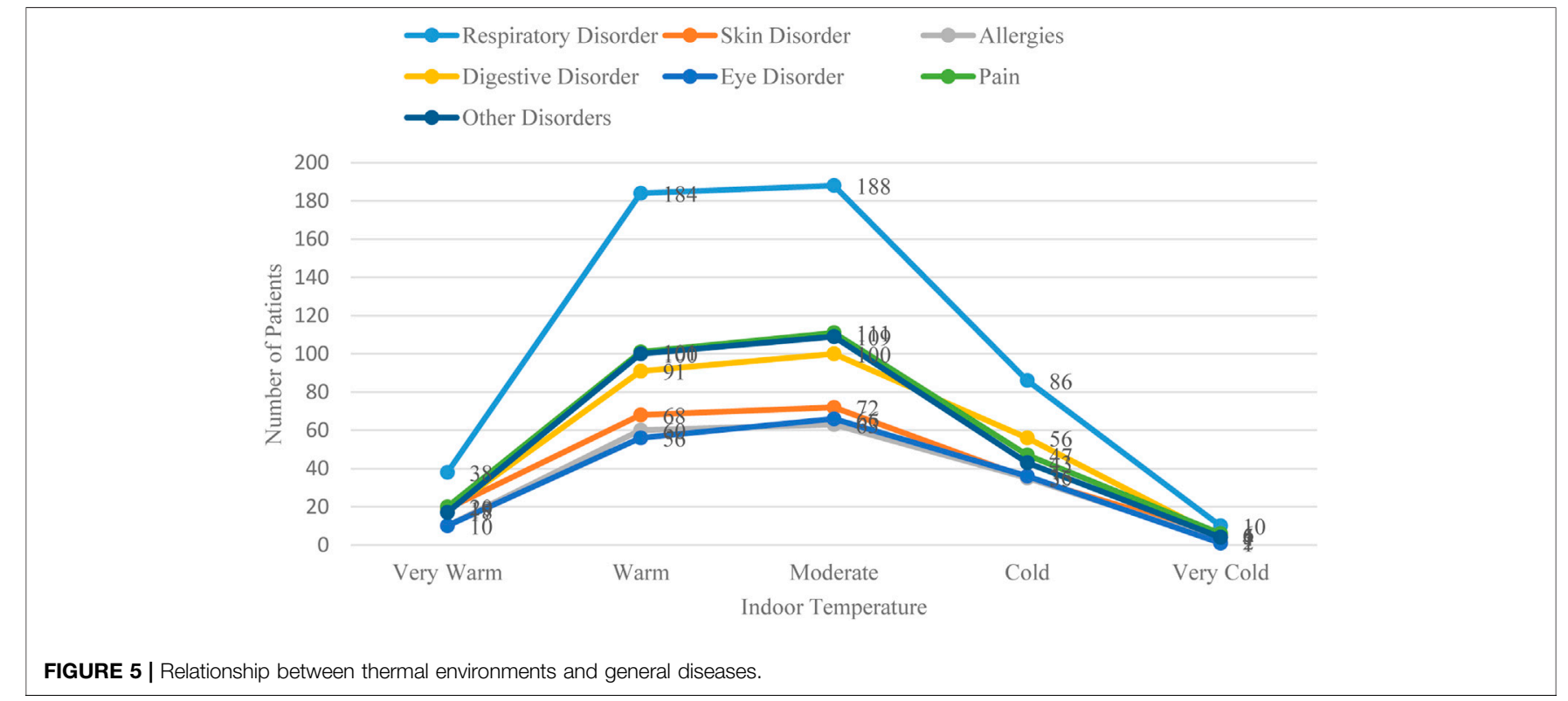

To investigate the occurrence of specific diseases, it was asked that the family members about their experiences of being treated for common diseases this winter (Table 3). As a result, nearly $90 \%$ of the respondents for respiratory diseases have experienced at least one treatment. The following were digestive diseases, pain, and other diseases, with $61-63 \%$ of them having medical experience. Overall, respondents had a very high level of experience in receiving treatment for various common diseases among their family members during the winter period. However, the experience of treatment for each of these seven types of disease did not 


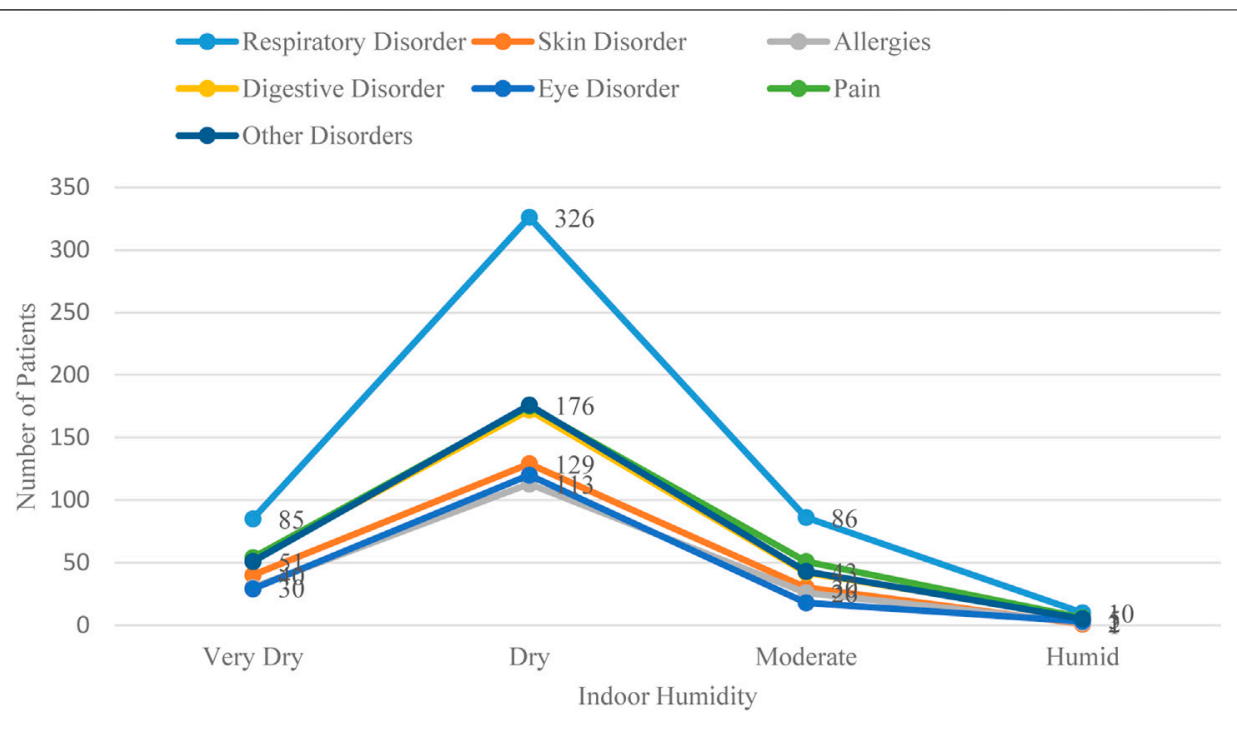

FIGURE 6 | Relationship between humidity environments and general diseases.

show any significant difference by the number of households, indicating that the treatment experienced daily was independent of the number of residents.

\section{The Relationship Between Residence Floor and Todai Health Index}

For the scale score for each of the 12 scales of the Todai Index, the sum of the items to which it belongs is usually used. However, since the number of items belonging to each scale is different, in this study, the average score of items belonging to each scale was used for analysis for the convenience of interpretation. Since each item is composed of a 3-point scale, the closer the scale is to 3 , the healthier it is. On all 12 scales, 2 or more points were scored, indicating that they were living an overall healthy life.

By the number of living floors, there was no significant difference in all 12 scales, so the Todai Index also shows that the health of residents does not differ according to the number of dwelling floors (Table 4). This trend is in line with the previous analysis of general health conditions. This is contrary to the claim that the higher you live, the more likely you are to have health problems in some previous studies. By the number of floors, there was no significant difference in all 12 categories, and the Todai Health Index also shows that the health of residents does not differ depending on the number of floors. This trend is in line with the previous analysis of general health conditions. As pointed out in some previous studies, this is contrary to the claim that the higher you live, the more likely you are to have health problems.

The 12 categories of the Todai Health Index are divided into five physical health and seven mental health categories. Therefore, by simplifying the 12 categories of Todai, five scales representing physical health were used as a group variable, and seven scales representing mental health were used as a group variable. By setting the scale to another group variable, the mean of the two group variables can be compared. As a result of comparing the scale scores of these two group variables, it was found that physical health had a relatively high score compared to mental health. The paired $t$-test, which verifies the difference between the two variables, showed that there was a statistically significant difference. In other words, high-rise residential building dwellers show relatively weaker mental health than their physical health (Table 5).

Among the scales belonging to mental health, the scale showing the lowest score is the "nervousness" scale, and the "irritability" and "lie" scales also show relatively low scores. However, this study cannot confirm whether this trend is a trend only for high-rise residential building dwellers or a general trend for city dwellers. Since all respondents in this study are high-rise residential building dwellers, it is difficult to compare them with the residents of other housing types. Therefore, whether this trend is a characteristic of high-rise apartments only or a general trend requires a wider range of studies to be able to identify a definite trend. However, the analysis result confirmed that mental health had a lower level than physical health and that this trend did not show any difference by the number of living groups. From this, it can be seen that the number of residents is not a factor that causes the difference in mental and physical health level.

\section{The Relationship Between Residence Floor and Indoor Temperature/Humidity}

The residential environment that affects the health of residents is more likely to be affected by the environmental characteristics, 


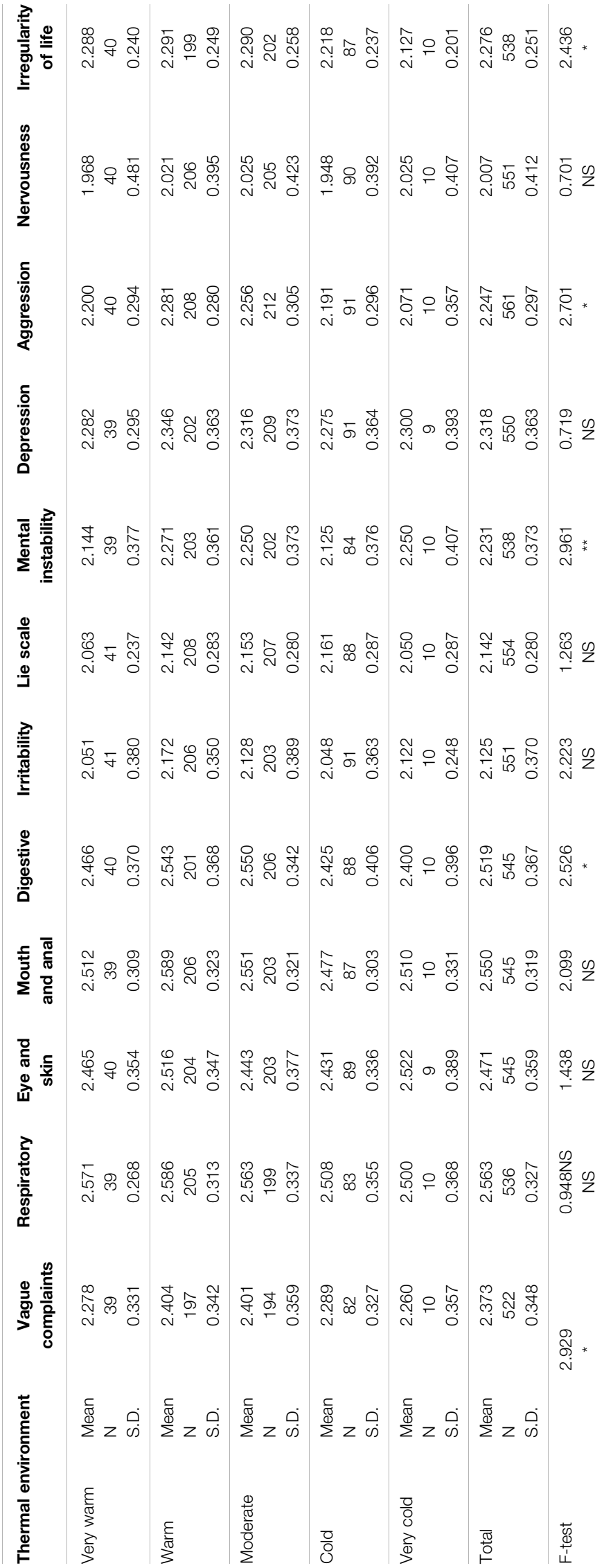

rather than the physical building characteristics, and compared to other countries, all the apartments in Dubai use centralized $\mathrm{A} / \mathrm{C}$; this is the reason why the survey is designed to separate indoor temperature and humidity.

Since indoor temperature and humidity in winter are likely to have a direct relationship with the physical health of residents, it is necessary to understand the relationship between indoor temperature and humidity in winter and the health of residents. In particular, temperature and humidity deteriorate the ventilation conditions due to the nature of apartment buildings that have an airtight space structure, while the insulation of the residential space is emphasized. It is worth noting that this is highly likely to cause health problems. As a result of the analysis, about $75 \%$ of the respondents answered that the indoor temperature was moderate or warm in the high-rise apartment, indicating that the heating condition in winter was good. However, in terms of humidity, $19.8 \%$ answered that it was adequate, while $77.7 \%$ answered that it was rather dry or fairly dry, indicating that the indoor air of high-rise apartments was generally dry. Also, in the indoor environment in winter, the number of living floors and temperature have a certain relationship, but humidity does not show a significant difference (Table 6).

\section{Indoor Temperature/Humidity and General Health Status}

The relationship between indoor temperature and humidity and daily health is characterized by two different factors. As a result of the analysis, it was found that the temperature in the indoor environment in winter did not have a clear relationship with the occurrence of daily diseases. In other words, the thermal environment showed a significant difference depending on the resident group, but it was found that the thermal environment itself was not related to the daily occurrence of diseases in most of the items (Figure 5). It can be seen that the pattern of disease occurrence does not change depending on how warm and cold the indoor space is in winter. However, the indoor humidity environment has a very deep relationship, and it was found that there was a significant difference according to the degree of indoor humidity in all items, except allergy among daily diseases. Therefore, the factor that has a deep relationship with disease occurrence among indoor environments is the indoor humidity environment, rather than the warm environment, and it can be evaluated that it has a very strong correlation (Figure 6).

However, unlike the warm environment, the indoor humidity environment does not show a significant difference with residence floors. Even if the indoor humidity environment is a factor that has a deep relationship with the disease occurrence of residents, it cannot be said that it has a relationship with the architectural characteristics, that is, the indoor humidity condition is a result of the indoor humidity environment formed, regardless of the number of living floors. It is judged that this is due to the factors other than the number of households, namely, the lifestyle and other factors each household has. 


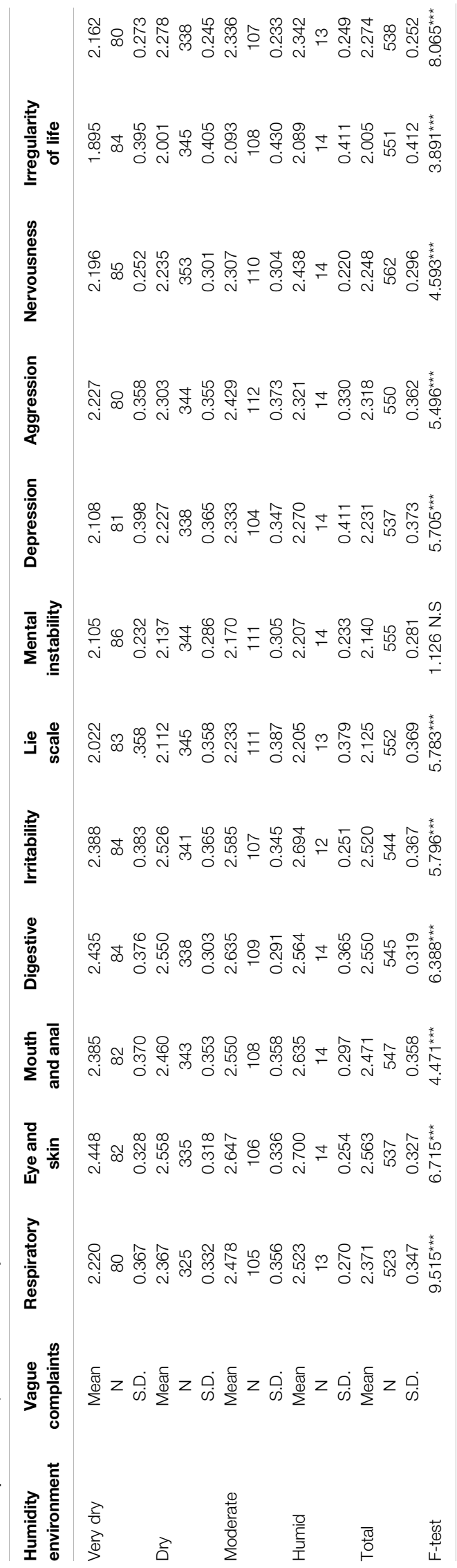

\section{Indoor Thermal Environment and Todai Health Index}

Looking at the relationship between indoor temperature and the 12 categories of Todai, some categories show differences in scale scores according to indoor temperature. Items showing differences in scale scores were analyzed on five scales: "vague complaints," "digestive," "mental instability," "aggression," and "irregularity of life." Looking at these in detail, the group that responded to "warm" and "moderate" was rated relatively high in health. "Very warm," "cold," and "very cold" showed relatively low scale scores in the group that responded. Although there is a slight difference among the groups of "warm" and "moderate," which were evaluated for high health, the group that responded to "warm" showed a slightly higher score. On the other hand, in the group with low health, the response group for "very warm" is similar to the response group for "cold," whereas the response group for "very cold" tends to show the lowest scale score.

By simplifying each of these categories, the results of comparing the 12 categories of Todai by grouping them into physical health items and mental health items show very interesting results. Grouping them has a problem of diluting individual characteristics by treating them as one group variable in 12 independent categories. However, it can be useful as a way of looking at overall trends. As a result of the analysis, the indoor thermal environment showed no significant difference with physical health items. However, there is a significant difference with mental health items. This means that the indoor thermal environment has a relatively high effect on mental health than on physical health among health effects. In the case of mental health items showing a significant difference, the response group showed high scores for "warm" and "moderate." It was found that a cold or too warm indoor environment had an adverse effect on mental health (Table 7).

\section{Indoor Humidity Environment and Todai Health Index}

As a result of verifying the difference according to the degree of indoor dryness or humidity for 12 categories of Todai, it was analyzed that there was a difference in all 11 items, except "lie scale" out of the 12 categories. This result is consistent with the analysis previously analyzed that indoor humidity has a significant relationship in the analysis of the relationship between indoor humidity and daily disease occurrence.

Among the responses to indoor humidity, "very humid" did not respond at all. As the dryness increases, the Todai scale score tends to be lower, indicating that dry indoor air has a negative effect on health. In addition, in about half of the 12 categories, the group responding to "humid" showed a higher scale score than the group responding to "moderate." Rather, it suggests that a slightly humid indoor environment is positive for health. These results suggest that indoor humidity is a central factor affecting the health of residents. This is because the indoor humidity conditions in both the daily occurrence of disease and the Todai Index show a difference under a fairly high level of significance.

As a result of analyzing the 12 categories of the Todai Index by dividing them into a group of physical health items and a group of mental health items, indoor humidity shows a significant difference in 
both group variables. It can be seen that the scale scores in both physical and mental health items are increasing as the group that responded that it is wet is increasing. These results again show that a slightly humid indoor environment has a positive effect on health, whether it be physical or mental health, rather than a dry environment. Therefore, the daily disease occurrence and Todai Index analyzed before show the same results in the relationship between the indoor temperature and humidity environment (Table 8).

\section{CONCLUSION}

The correlation between architectural and indoor environmental characteristics and health was analyzed for the residents of highrise residential buildings in Dubai. Residents' health in high-rise residential buildings in Dubai had never been evaluated with any self-reported health evaluation tools, even though Dubai is one of the most well-known cities of skyscrapers.

As a result of the analysis, as has been pointed out before, the point that the higher you go to the higher floors, the negative impact on the health of residents is not verified. These results were found to be independent of the number of floors in the selfassessment of overall health, changes in the health status compared to 1 year ago, occurrence of daily diseases, and health evaluation by the Todai Health Index. It can be determined that there is no relationship between the residence floor and health. As pointed out in some of the previous studies, this result is contrary to the point that the higher you go, the more negative the health of the residents. The average residence period of Princess Tower residents is not long, and due to the differences in lifestyles, it suggests that the results of previous studies may not be applied to Dubai residents. Moreover, the limitation of this research was the size of the sample. It was not big and diverse enough. For future research, similar size high-rise residential buildings such as 23 Marina (90 floors, $393 \mathrm{~m}$ ), Elite Residence (91 floors, $381 \mathrm{~m}$ ), The Marina Torch ( 80 floors, $348 \mathrm{~m}$ ), Cayan Tower (76 floors, $330 \mathrm{~m}$ ), and HHHR Tower (72 floors, $317 \mathrm{~m}$ ) in Dubai Marina should be investigated simultaneously via selfreported health evaluation based on the Todai Index.

Among the indoor environmental characteristics, the thermal environment has a significant correlation with the residence floors, but the effect of the thermal environment itself on health has a weak correlation with physical health. However, it was analyzed that the humidity environment in winter has a very direct relationship with the health of residents. On the other hand, the indoor humidity was analyzed to be independent of the number of living floors, so it was

\section{REFERENCES}

Acuto, M. (2010). High-rise Dubai Urban Entrepreneurialism and the Technology of Symbolic Power. Cities 27 (4), 272-284. doi:10.1016/j.cities.2010.01.003

Ahmed, K. G. (2012). A 'Fareej-In-The-Sky': Towards A Community-Oriented Design for High-Rise Residential Buildings in the UAE. Ohi 37 (1), 48-70. doi:10.1108/ohi-01-2012-b0006

Ahn, H., Son, S., Park, K., and Kim, S. (2021). Cost Assessment Model for Sustainable Health and Safety Management of High-Rise Residential judged that the number of dwelling floors did not act as a mediating variable of the humidity. Humidity has a very close relationship not only with the occurrence of daily diseases of residents but also with the health evaluation analyzed by the Todai Index, a more structured self-response health evaluation tool. It was found that there is a deep relationship between both physical and mental health. The humid environment had a more negative effect on health in the dry case. Rather, it was analyzed that a slightly humid condition had a positive effect on health. Therefore, in future research, it is necessary to devise architectural measures that can positively affect the health of residents by conducting research to explore the architectural factors or lifestyle characteristics that form a mild humid environment in the hot desert weather.

\section{DATA AVAILABILITY STATEMENT}

The original contributions presented in the study are included in the article/Supplementary Material; further inquiries can be directed to the corresponding author.

\section{ETHICS STATEMENT}

The studies involving human participants were reviewed and approved by the Ethics Committee of Ajman University. The patients/participants provided their written informed consent to participate in this study.

\section{AUTHOR CONTRIBUTIONS}

All authors contributed significantly to this study. CJ and JA identified and secured the example buildings used in the study. The data acquisition system and installations of sensors were designed and installed by CJ and JA. JA was responsible for data collection. Data analysis was performed by CJ. The manuscript was compiled by CJ and reviewed by JA. All authors have read and agreed to the published version of the manuscript.

\section{ACKNOWLEDGMENTS}

The authors would like to express their gratitude to Ajman University for the generous support to publish this article.

Buildings in Korea. J. Asian Architecture Building Eng. 1, 12. doi:10.1080/ 13467581.2021.1902334

Alawadi, K., and Benkraouda, O. (2019). The Debate over Neighborhood Density in Dubai: Between Theory and Practicality. J. Plann. Edu. Res. 39 (1), 18-34. doi:10.1177/0739456x17720490

Alawadi, K. (2017). Rethinking Dubai's Urbanism: Generating Sustainable FormBased Urban Design Strategies for an Integrated Neighborhood. Cities 60, 353-366. doi:10.1016/j.cities.2016.10.012

AnhangPrice, R., Elliott, M. N., Zaslavsky, A. M., Hays, R. D., Lehrman, W. G., Rybowski, L., et al. (2014). Examining the Role of Patient Experience Surveys in 
Measuring Health Care Quality. Med. Care Res. Rev. 71 (5), 522-554. doi:10.1177/1077558714541480

$\mathrm{Au}, \mathrm{N}$., and Johnston, D. W. (2014). Self-assessed Health: what Does it Mean and what Does it Hide? Soc. Sci. Med. 121, 21-28. doi:10.1016/ j.socscimed.2014.10.007

Baghianimoghadam, M. H., Sharifirad, G., Rahaei, Z., Baghianimoghadam, B., and Heshmati, H. (2011). Health Related Quality of Life in Children with Thalassaemia Assessed on the Basis of SF-20 Questionnaire in Yazd, Iran: a Case-Control Study. Cent. Eur. J. Public Health 19 (3), 165-169. doi:10.21101/cejph.a3640

Barr, J., and Johnson, J. (2020). Skyscrapers and the Happiness of Cities. East. Econ. J. 46 (2), 344-377. doi:10.1057/s41302-019-00163-2

Barros, P., Ng Fat, L., Garcia, L. M. T., Slovic, A. D., Thomopoulos, N., de Sá, T. H., et al. (2019). Social Consequences and Mental Health Outcomes of Living in High-Rise Residential Buildings and the Influence of Planning, Urban Design and Architectural Decisions: A Systematic Review. Cities 93, 263-272. doi:10.1016/j.cities.2019.05.015

Breslow, H. (2020). The Smart City and the Containment of Informality: The Case of Dubai. Urban Stud. 58 (3), 471-486. doi:10.1177/0042098020903233

Buckley, M., and Hanieh, A. (2014). Diversification by Urbanization: Tracing the Property-Finance Nexus in Dubai and the Gulf. Int. J. Urban Reg. Res. 38 (1), 155-175. doi:10.1111/1468-2427.12084

Burholt, V., and Nash, P. (2011). Short Form 36 (SF-36) Health Survey Questionnaire: Normative Data for Wales. J. Public Health 33 (4), 587-603. doi:10.1093/pubmed/fdr006

Busija, L., Pausenberger, E., Haines, T. P., Haymes, S., Buchbinder, R., and Osborne, R. H. (2011). Adult Measures of General Health and HealthRelated Quality of Life: Medical Outcomes Study Short Form 36-Item (SF36) and Short Form 12-Item (SF-12) Health Surveys, Nottingham Health Profile (NHP), Sickness Impact Profile (SIP), Medical Outcomes Study Short Form 6D (SF-6D), Health Utilities Index Mark 3 (HUI3), Quality 557 of Well-Being Scale (QWB), and Assessment of Quality of Life (AQOL) . Arthritis Care Res. 63 (S11), S383-S412. doi:10.1002/acr.20541

Cho, S. H., and Lee, T. K. (2011). A Study on Building Sustainable Communities in High-Rise and High-Density Apartments - Focused on Living Program. Building Environ. 46 (7), 1428-1435. doi:10.1016/j.buildenv.2011.01.004

Choi, Y. J., and Matz-Costa, C. (2018). Perceived Neighborhood Safety, Social Cohesion, and Psychological Health of Older Adults. Gerontologist 58 (1), 196-206. doi:10.1093/geront/gnw187

Crook, B., and Burton, N. C. (2010). Indoor Moulds, Sick Building Syndrome and Building Related Illness. Fungal Biol. Rev. 24 (3-4), 106-113. doi:10.1016/ j.fbr.2010.05.001

Doiron, D., Fiebig, D. G., Johar, M., and Suziedelyte, A. (2015). Does Self-Assessed Health Measure Health? Appl. Econ. 47 (2), 180-194. doi:10.1080/ 00036846.2014 .967382

Dubai Statistics Center (2021). Dubai in Figures 2021: Housing \& Building. Available at: https://www.dsc.gov.ae/Report/DSC_SYB_2020_02_02.pdf.

Elessawy, F. (2017). The Boom: Population and Urban Growth of Dubai City. Horizons Hum. Soc. Sci. 2, 26-41. doi:10.19089/hhss.v2i2.60

Emmanuel, U., Osondu, E. D., and Kalu, K. C. (2020). Architectural Design Strategies for Infection Prevention and Control (IPC) in Health-Care Facilities: towards Curbing the Spread of Covid-19. J. Environ. Health Sci. Eng., 18, 1-9. doi:10.1007/s40201-020-00580-y

Ewers, M. C. (2017). International Knowledge Mobility and Urban Development in Rapidly Globalizing Areas: Building Global Hubs for talent in Dubai and Abu Dhabi. Urban Geogr. 38 (2), 291-314. doi:10.1080/ 02723638.2016.1139977

Fazli, R. F., and Faridi, R. A. (2008). Urbanization in Dubai: Process, Problems and Challenges. J. West Asian Stud. 22 (1), 201-209.

Foster, S., Hooper, P., Kleeman, A., Martino, E., and Giles-Corti, B. (2020). The High Life: A Policy Audit of Apartment Design Guidelines and Their Potential to Promote Residents' Health and Wellbeing. Cities 96, 102420. doi:10.1016/ j.cities.2019.102420

Furutani, K., Kawamoto, T., Alimardani, M., and Nakashima, K. I. (2020). Exhausted Parents in Japan: Preliminary Validation of the Japanese Version of the Parental Burnout Assessment. New Dir. Child Adolesc. Dev. 2020 (174), 33-49. doi:10.1002/cad.20371

Garratt, A. M., and Stavem, K. (2017). Measurement Properties and Normative Data for the Norwegian SF-36: Results from a General
Population Survey. Health Qual. Life Outcomes 15 (1), 51-10. doi:10.1186/s12955-017-0625-9

Generalova, E. M. (2018). Architectural Typology of High-Rise Housing in Dubai. Urban $\bigoplus_{i}$ onstruction and Architecture 8 (4), 105-111.

Ghaffarianhoseini, A., AlWaer, H., Omrany, H., Ghaffarianhoseini, A., Alalouch, C., Clements-Croome, D., et al. (2018). Sick Building Syndrome: Are We Doing Enough? Architectural Sci. Rev. 61 (3), 99-121. doi:10.1080/ 00038628.2018 .1461060

Guyot, G., Sherman, M. H., and Walker, I. S. (2018). Smart Ventilation Energy and Indoor Air Quality Performance in Residential Buildings: A Review Energy Build. 165, 416-430.

Hu, Y., van Lenthe, F. J., Borsboom, G. J., Looman, C. W. N., Bopp, M., Burström, B., et al. (2016). Trends in Socioeconomic Inequalities in SelfAssessed Health in 17 European Countries between 1990 and 2010. J. Epidemiol. Community Health 70 (7), 644-652. doi:10.1136/jech-2015206780

Ige, J., Pilkington, P., Orme, J., Williams, B., Prestwood, E., Black, D., et al. (2019). The Relationship between Buildings and Health: a Systematic Review. J. Public Health 41 (2), e121-e132. doi:10.1093/pubmed/fdy138

Jafari, M. J., Khajevandi, A. A., Mousavi Najarkola, S. A., Yekaninejad, M. S., Pourhoseingholi, M. A., Omidi, L., et al. (2015). Association of Sick Building Syndrome with Indoor Air Parameters. Tanaffos 14 (1), 55-62.

Kalantari, S., and Shepley, M. (2020). Psychological and Social Impacts of HighRise Buildings: a Review of the post-occupancy Evaluation Literature. Housing Stud. 36,2021 (8), 1-30. doi:10.1080/02673037.2020.1752630

Kim, J.-H., Kang, S.-H., and Jeong, M.-A. (2010). Assessment on Quality of Life: Based on Oral Health Conditions. J. Korea Academia-Industrial Cooperation Soc. 11 (12), 4873-4880. doi:10.5762/kais.2010.11.12.4873

Larcombe, D. L., Etten, E., Logan, A., Prescott, S. L., and Horwitz, P. (2019). HighRise Apartments and Urban Mental Health-Historical and Contemporary Views. Challenges 10 (2), 34. doi:10.3390/challe10020034

Lee, H. (2014). Psychological Characteristics of High-Rise Residents. Int. J. Sust. Building Tech. Urban Dev. 5 (1), 10-20. doi:10.1080/ 2093761x.2014.876905

Lee, S., O'Neill, A. H., Ihara, E. S., and Chae, D. H. (2013). Change in Self-Reported Health Status Among Immigrants in the United States: Associations with Measures of Acculturation. PloS one 8 (10), e76494. doi:10.1371/ journal.pone.0076494

Lesage, F.-X., Martens-Resende, S., Deschamps, F., and Berjot, S. (2011). Validation of the General Health Questionnaire (GHQ-12) Adapted to a Work-Related Context. Ojpm 01 (02), 44-48. doi:10.4236/ ojpm.2011.12007

Lin, X.-J., Lin, I.-M., and Fan, S.-Y. (2013). Methodological Issues in Measuring Health-Related Quality of Life. Tzu Chi Med. J. 25 (1), 8-12. doi:10.1016/ j.tcmj.2012.09.002

Lindkvist, M., and Feldman, I. (2016). Assessing Outcomes for Cost-Utility Analysis in Mental Health Interventions: Mapping Mental Health Specific Outcome Measure GHQ-12 onto EQ-5D-3L. Health Qual. Life Outcomes 14 (1), 134-139. doi:10.1186/s12955-016-0535-2

Lins, L., and Carvalho, F. M. (2016). SF-36 Total Score as a Single Measure of Health-Related Quality of Life: Scoping Review. SAGE Open Med. 4, 2050312116671725. doi:10.1177/2050312116671725

Lu, C. Y., Tsai, M. C., Muo, C. H., Kuo, Y. H., Sung, F. C., and Wu, C. C. (2018). Personal, Psychosocial and Environmental Factors Related to Sick Building Syndrome in Official Employees of Taiwan. Int. J. Environ. Res. Public Health 15 (1), 7. doi:10.3390/ijerph15010007

LULUC (2021). Urbanization in Dubai: Critical Statistics, Causes \& Impacts. Available at: https://www.lcluc.umd.edu/hotspot/urbanization-dubai (Accessed June 12, 2021).

Manyazewal, T. (2017). Using the World Health Organization Health System Building Blocks through Survey of Healthcare Professionals to Determine the Performance of Public Healthcare Facilities. Arch. Public Health 75 (1), 50-58. doi:10.1186/s13690-017-0221-9

Meier, B. M. (2010). 8 the World Health Organization, the Evolution of Human Rights, and the Failure to Achieve Health for All. Glob. Health Hum. Rights Leg. Phil. Perspect. 1, 163.

Murayama, Y., Inoue, K., Yamazaki, C., Kameo, S., Nakazawa, M., and Koyama, H. (2019). Association between Depressive State and Lifestyle Factors Among 
Residents in a Rural Area in Japan: A Cross-Sectional Study. Tohoku J. Exp. Med. 249 (2), 101-111. doi:10.1620/tjem.249.101

Nassar, A. K., Alan Blackburn, G., and Duncan Whyatt, J. (2014). Developing the Desert: The Pace and Process of Urban Growth in Dubai. Comput. Environ. Urban Syst. 45, 50-62. doi:10.1016/j.compenvurbsys.2014.02.005

Nguyen, J. L., Schwartz, J., and Dockery, D. W. (2014). The Relationship between Indoor and Outdoor Temperature, Apparent Temperature, Relative Humidity, and Absolute Humidity. Indoor air 24 (1), 103-112. doi:10.1111/ina.12052

Persily, A. K., and Emmerich, S. J. (2012). Indoor Air Quality in Sustainable, Energy Efficient Buildings. HvaceR Res. 18 (1-2), 4-20. 10.1080/10789669. 2011.592106.

Safarik, D., Ursini, S., and Wood, A. (2018). Urban Habitat. CTBUH J. 4 (4), $20-29$.

Saimanen, I., Kuosmanen, V., Rahkola, D., Selander, T., Kärkkäinen, J., Harju, J., et al. (2019). RAND-36-Item Health Survey: A Comprehensive Test for LongTerm Outcome and Health Status Following Surgery. Anticancer Res. 39 (6), 2927-2933. doi:10.21873/anticanres.13422

Sivakumar, I., Manimekalai, K., and Ranjithkumar, A. (2019). Accessing Public Health Facilities: Rural and Urban Disparities. J. Crit. Rev. 7 (3), 2020. doi: $10.31838 /$ jcr. 07.03 .73

Smith, A. B., Fallowfield, L. J., Stark, D. P., Velikova, G., and Jenkins, V. (2010). A Rasch and Confirmatory Factor Analysis of the General Health Questionnaire (GHQ)--12. Health Qual. Life Outcomes 8 (1), 45-10. doi:10.1186/1477-7525$8-45$

Steinemann, A., Wargocki, P., and Rismanchi, B. (2017). Ten Questions Concerning green Buildings and Indoor Air Quality. Building Environ. 112, 351-358. doi:10.1016/j.buildenv.2016.11.010

Subedi, R. P., and Rosenberg, M. W. (2014). Determinants of the Variations in Self-Reported Health Status Among Recent and More Established Immigrants in Canada. Soc. Sci. Med. 115, 103-110. doi:10.1016/ j.socscimed.2014.06.021

Sullivan, P. W., Slejko, J. F., Sculpher, M. J., and Ghushchyan, V. (2011). Catalogue of EQ-5D Scores for the United Kingdom. Med. Decis. Making 31 (6), 800-804. doi:10.1177/0272989x11401031

Suzuki, S. (2017). Exhausting Physicians Employed in Hospitals in Japan Assessed by a Health Questionnaire. SanEiShi 59 (4), 107-118. doi:10.1539/ sangyoeisei.16-022-e

Tabali, M., Jeschke, E., Dassen, T., Ostermann, T., and Heinze, C. (2012). The Nottingham Health Profile: a Feasible Questionnaire for Nursing home Residents? Int. Psychogeriatr. 24 (3), 416-424. doi:10.1017/s1041610211001931

Takigawa, T., Saijo, Y., Morimoto, K., Nakayama, K., Shibata, E., Tanaka, M., et al. (2012). A Longitudinal Study of Aldehydes and Volatile Organic Compounds Associated with Subjective Symptoms Related to Sick Building Syndrome in New Dwellings in Japan. Sci. Total Environ. 417-418, 61-67. doi:10.1016/ j.scitotenv.2011.12.060

ten Klooster, P. M., Vonkeman, H. E., Taal, E., Siemons, L., Hendriks, L., de Jong, A. J., et al. (2013). Performance of the Dutch SF-36 Version 2 as a Measure of Health-Related Quality of Life in Patients with Rheumatoid Arthritis. Health Qual. Life Outcomes 11 (1), 77-79. doi:10.1186/1477-7525-11-77

Tham, K. W. (2016). Indoor Air Quality and its Effects on Humans-A Review of Challenges and Developments in the Last 30 Years. Energy and Buildings 130, 637-650. doi:10.1016/j.enbuild.2016.08.071
Trieu, B. L., Nguyen, T. T. H. N., Nguyen, T. L., Morinaga, M., Hiraguri, Y., Yano, T., et al. (2021). Change in the Self-Reported Health Status of Residents Associated with the Reduced Aircraft Noise Around Tan Son Nhat Airport after the Epidemic Outbreak. INTER-NOISE NOISE-CON Congress Conf. Proc. 263 (1), 5511-5522. doi:10.3397/in-2021-3128

Van Cauwenberg, J., De Bourdeaudhuij, I., De Meester, F., Van Dyck, D., Salmon, J., Clarys, P., et al. (2011). Relationship between the Physical Environment and Physical Activity in Older Adults: a Systematic Review. Health \& Place 17 (2), 458-469. doi:10.1016/j.healthplace.2010.11.010

Van den Berg, M., Wendel-Vos, W., Van Poppel, M., Kemper, H., van Mechelen, W., and Maas, J. (2015). Health Benefits of green Spaces in the Living Environment: A Systematic Review of Epidemiological Studies. Urban For. Urban Green. 14 (4), 806-816. doi:10.1016/ j.ufug.2015.07.008

Van Hout, B., Janssen, M. F., Feng, Y.-S., Kohlmann, T., Busschbach, J., Golicki, D., et al. (2012). Interim Scoring for the EQ-5D-5L: Mapping the EQ-5D-5L to EQ5D-3L Value Sets. Value in health 15 (5), 708-715. doi:10.1016/ j.jval.2012.02.008

Wolkoff, P. (2018). Indoor Air Humidity, Air Quality, and Health - an Overview. Int. J. Hyg. Environ. Health 221 (3), 376-390. doi:10.1016/ j.ijheh.2018.01.015

Wong, Y. J., Ho, M. H. R., Wang, S. Y., and Miller, I. S. (2017). Meta-Analyses of the Relationship Between Conformity to Masculine Norms and Mental Health-Related Outcomes. J. Couns. Psychol. 64 (1), 80.

Xue, F., Gou, Z., and Lau, S. (2016a). Human Factors in green Office Building Design: The Impact of Workplace green Features on Health Perceptions in High-Rise High-Density Asian Cities. Sustainability 8 (11), 1095. doi:10.3390/ su8111095

Xue, P., Mak, C. M., and Ai, Z. T. (2016b). A Structured Approach to Overall Environmental Satisfaction in High-Rise Residential Buildings. Energy and Buildings 116, 181-189. doi:10.1016/j.enbuild.2016.01.006

Zimmerman, F. J., and Anderson, N. W. (2019). Trends in Health Equity in the United States by Race/ethnicity, Sex, and Income, 1993-2017. JAMA Netw. Open 2 (6), e196386. doi:10.1001/jamanetworkopen.2019.6386

Conflict of Interest: The authors declare that the research was conducted in the absence of any commercial or financial relationships that could be construed as a potential conflict of interest.

Publisher's Note: All claims expressed in this article are solely those of the authors and do not necessarily represent those of their affiliated organizations, or those of the publisher, the editors, and the reviewers. Any product that may be evaluated in this article, or claim that may be made by its manufacturer, is not guaranteed or endorsed by the publisher.

Copyright (C) 2021 Jung, Awad and Al Qassimi. This is an open-access article distributed under the terms of the Creative Commons Attribution License (CC BY). The use, distribution or reproduction in other forums is permitted, provided the original author(s) and the copyright owner(s) are credited and that the original publication in this journal is cited, in accordance with accepted academic practice. No use, distribution or reproduction is permitted which does not comply with these terms. 